\title{
FAKTOR-FAKTOR YANG MEMPENGARUHI PREFERENSI MASYARAKAT TERHADAP RUSUNAWA BRUJUL
}

\author{
Suci Kusumaningsihc, Winny Astuti' ${ }^{1}$, Erma Fitria Rini ${ }^{1}$ \\ 1Program Studi Perencanaan Wilayah dan Kota Fakultas Teknik Universitas Sebelas Maret
}

\begin{abstract}
Abstrak
Pembangunan daerah saat ini sedang dilakukan oleh pemerintah daerah di Indonesia. Salah satu dampak dari pembangunan daerah adalah timbulnya urbanisasi. Urbanisasi tidak selamanya membawa dampak baik. Salah satu dampak buruk dari urbanisasi adalah munculnya rumah tidak layak huni. Salah satu program yang dilakukan oleh Pemerintah Kabupaten Karanganyar adalah dengan membangun rumah susun sederhana sewa sebagai alternatif hunian bagi masyarakat berpenghasilan rendah. Rusunawa yang dibangun oleh Pemerintah Kabupaten Karanganyar adalah Rusunawa Brujul yang terletak di Kecamatan Jaten. Akan tetapi dalam realisasinya, Rusunawa Brujul tidak diminati oleh masyarakat. Dari 192 unit yang disediakan, terdapat 90 unit yang tidak berpenghuni. Beberapa faktor yang menyebabkan kurang diminatinya rusun adalah tingkat kenyamanan yang rendah, kualitas bangunan yang hampir sama dengan rumah kumuh serta harga yang sulit dijangkau. Tujuan dari penelitian ini untuk mengetahui faktor dominan yang mempengaruhi rendahnya preferensi masyarakat terhadap Rusunawa Brujul. Penelitian ini menggunakan metode kuantitatif dengan analisis faktor. Hasil penelitian ini menunjukkan bahwa terdapat tiga faktor dominan yang mempengaruhi rendahnya preferensi masyarakat terhadap Rusunawa Brujul. Ketiga faktor tersebut adalah (1) faktor keadaan rusun $(71,89 \%),(2)$ faktor keterjangkauan terhadap fasilitas (5,49\%), dan (3) faktor sosial ekonomi (4,78\%). Berdasarkan penelitian ini disarankan agar Pemerintah Kabupaten Karanganyar lebih berperan aktif dalam pemeliharaan kualitas dari rusun supaya minat masyarakat terhadap Rusunawa Brujul meningkat.
\end{abstract}

Kata kunci: Faktor-Faktor Penyebab; Rumah Susun Sederhana Sewa

\begin{abstract}
Regional development is currently being encouraged by local government in Indonesia. One of the effects of regional development is urbanization. Urbanization is not always bring good impact. One of the impact of urbanization is the appearance of the slum housing. One of the programs undertaken by the Government of Karanganyar Regency is by build a low cost rented apartment as an alternative residence for low-income communities. Low cost rented apartment built by the Government of Karanganyar Regency is located in Brujul, Jaten. However in reality, the community is not interested to live in Brujul low cost rented apartment. Out of 192 unit provided, there were 90 units are empty. Some of the factors that lead to less interest low cost rented apartment is a low level of comfort, the quality of the building similar to the slums and the prices that are hard to reach. The purpose of this research is to analyze the dominant factors that influence Community the low preference towards Brujul low cost rented apartment. These studies used quantitative methods with factor analysis. The results of this research show that there are three dominant factors that influence Community the low preference towards Brujul low cost rented apartment. The third factors are: (1) Condition of low cost rented apartment factors (71.89\%), (2) affordability towards facilities factors (5.49\%), and (3) socio-economic factors (4.78\%). Based on this research it is recommended that Governments of the Karanganyar Regency has to improve their role in the maintaining the quality of their low cost rented apartment so that people's interest towards Rusunawa Brujul increases.
\end{abstract}

Keywords: Cause Factors; Low Cost Rented Apartment

\section{PENDAHULUAN}

Pembangunan daerah saat ini sedang digalakkan oleh pemerintah daerah di Indonesia. Pembangunan ini bertujuan untuk meningkatkan kesejahteraan masyarakat. Akan tetapi pembangunan yang ada terkadang tidak merata, sehingga terdapat ketimpangan pembangunan antar daerah. Salah satu dampak negatif dari pembangunan adalah timbulnya urbanisasi yang juga akan membawa dampak negatif bagi daerah yang menjadi tujuan urbanisasi. Salah satunya adalah semakin tingginya kepadatan penduduk yang menyebabkan bertambah pula kebutuhan akan tempat tinggal. Meningkatnya kebutuhan akan tempat tinggal tidak berbanding lurus dengan ketersediaan lahan sehingga menyebabkan harga lahan menjadi tinggi. Tingginya harga lahan menyebabkan banyaknya permukiman-permukiman kumuh muncul. Untuk mengatasi masalah tersebut, pemerintah daerah mempunyai solusi, salah satunya adalah dengan membangun rumah susun bagi masyarakat menengah kebawah. 
Kabupaten Karanganyar merupakan kabupaten dengan jumlah penduduk sebesar 856.198 jiwa dengan tingkat pertumbuhan sebesar $0,988 \%$. Pertumbuhan penduduk ini membuat pemerintah berupaya untuk memenuhi kebutuhan penduduknya, salah satunya adalah kebutuhan akan rumah layak huni. Kecamatan Jaten merupakan salah satu kecamatan di Kabupaten Karanganyar yang ditetapkan menjadi kawasan industri sehingga banyak terdapat industri yang berkembang.

Pada tahun 2008, Menteri Perumahan Rakyat dan Menteri Tenaga Kerja dan Transmigrasi membangun rumah susun di Kecamatan Jaten yang diperuntukkan untuk buruh di Kecamatan Jaten. Rumah susun tersebut berada di Desa Brujul dan lebih dikenal dengan Rusunawa Brujul. Tujuan pembangunan rusunawa ini pada awalnya adalah untuk menyediakan hunian yang layak bagi pekerja. Akan tetapi pekerja yang merupakan sasaran awal dari pembangunan rusun tidak berminat untuk tinggal di Rusunawa Brujul, sehingga Rusunawa Brujul diperuntukkan untuk masyarakat umum yang merupakan masyarakat berpenghasilan rendah. Menurut Nugroho (2014) terdapat beberapa faktor yang menyebabkan kurang diminatinya rumah susun sederhana yakni, masyarakat yang tidak mengetahui keberadaan rusunawa, masyarakat mengetahui keberadaan rusunawa akan tetapi tidak mengetahui kondisi di dalam rusunawa, masyarakat mengetahui kondisi rusunawa tetapi tidak berminat, masyarakat sudah betah tinggal di kos/kontrakan, masyarakat memiliki ketakutan jika tinggal di rumah susun maka anak-anak mereka yang masih kecil akan jatuh dari lantai atas, serta adanya anggapan bahwa rumah yang ditinggali harus merupakan rumah yang menapak dengan tanah.

Berdasarkan isu tersebut yang melatarbelakangi dilakukannya penelitian di Kecamatan Jaten mengenai faktor dominan yang mempengaruhi rendahnya preferensi masyarakat terhadap Rusunawa Brujul. Penelitian ini diharapkan dapat digunakan sebagai dasar pertimbangan dalam membangun minat masyarakat untuk tinggal di Rusunawa Brujul yang ada di Kecamatan Jaten.

\section{KAJIAN TEORI}

Rumah susun sederhana sewa merupakan bangunan gedung bertingkat yang dibangun dalam suatu lingkungan yang terbagi dalam bagian-bagian yang distrukturkan secara fungsional dalam arah horizontal maupun vertikal dan merupakan satuan-satuan yang masing-masing digunakan secara terpisah, status penguasaannya sewa serta dibangun dengan menggunakan dana Anggaran Pendapatan dan Belanja Negara dan/atau Anggaran Pendapatan Belanja Daerah dengan fungsi utamanya sebagai hunian (Peraturan Menteri Negara Perumahan Rakyat Nomor: 9/PERMEN/M/2008)

Menurut Nasution (2004:45) terdapat beberapa pertimbangan dalam memilih lokasi rumah/tempat tinggal, yaitu: (1) Pemilihan lokasi rumah dengan jarak relatif dekat ke sekolah, tempat kerja, pasar, rumah keluarga lain/sahabat dan fasilitas lainnya / Aksesibilitas (2) Harga lahan, harga rumah, biaya sewa, kemudahan untuk dipindahtangankan (3) Faktor jarak terdiri dari jarak linier dan jarak ekologis (4) Posisi keluarga dalam lingkup sosial, lingkup perumahan dan lingkup komunitas dan (5) Privasi dan Kenyamanan

Menurut Sasmito (2014), terdapat faktor-faktor yang menyebabkan kurang diminatinya rumah susun sederhana, yaitu: (1) Tingkat kenyamanan lingkungan di rumah susun dirasakan masih kurang; (2) Kualitas bangunan rumah susun tidak jauh berbeda dengan kondisi di permukiman kumuh; (3) Masyarakat senang beraktifitas di luar ruangan khususnya interaksi sosial; (4) Masyarakat belum terbiasa terbebani dengan kewajiban pemeliharaan bangunan rumah susun demi kepentingan bersama; (5) Pengetahuan masyarakat terhadap teknologi baru yang diterapkan di rumah susun masih minim; (6) Budaya masyarakat yang tidak terbiasa tinggal di rumah bertingkat dan senang berdekatan dengan sanak saudara; (7) Desain rumah susun yang kurang humanis khususnya bagi lansia; (8) Harga yang sulit dijangkau; (9) Rumah merupakan jati diri dan ajang penuangan kreatifitas penghuni; (10) Budaya masyarakat yang lebih tenang jika memiliki tanah sendiri sebagai bentuku investasi; (11) Area privasi dirasa masih minim; dan (12) Masyarakat senang membuka usaha sambilan di rumah.

\section{METODE PENELITIAN}

Penelitian in merupakan penelitian yang menggunakan pendekatan deduktif. Populasi dalam penelitiain ini adalah seluruh masyarakat berpenghasilan rendah (MBR) Kecamatan Jaten yang belum memiliki rumah dan memiliki rumah yang tidak layak huni. Jumlah masyarakat berpenghasilan rendah di Kecamatan Jaten berjumlah 4.482 KK. Berdasarkan populasi yang ada, maka ditentukan sampel yang diambil berdasarkan proporsi jumlah keluarga yang memenuhi syarat untuk menempati Rusunawa Brujul. Penentuan jumlah sampel menggunakan teori dari Hair et al 
(1998:637) dalam Harianto (2006:27) menyatakan bahwa jumlah sampel yang diambil minimal 5 kali dari jumlah parameter yang digunakan dalam penelitian.

$$
\begin{gathered}
\text { Parameter } \times 5=\text { Sampel } \\
23 \times 5=115 \text { sampel }
\end{gathered}
$$

Sampel dalam penelitian ini dibulatkan menjadi 120 sampel. Jenis dan sumber data dalam penelitian ini adalah data primer dan data sekunder. Data primer berupa informasi yang diperoleh dari wawancara dengan pengelola rusun, observasi dan juga kuisioner dengan responden masyarakat berpenghasilan rendah dengan menggunakan pertanyaan, yang meliputi (1) Lokasi, (2) Fasilitas (3) Harga (4) Standar Unit Rusun (5) Keamanan (6) Kenyamanan dan (7) Lingkungan Sosial.

Data primer juga berupa observasi dilakukan dengan menggunakan daftar checklist mengenai (1) Kondisi Rusunawa dan (2) Fasilitas Umum Kabupaten. Sedangkan data sekunder sebagai data pendukung diperoleh melalui dokumentasi, yaitu (1) Lokasi fasilitas umum kabupaten, diperolah dari Bappeda Kabupaten Karanganyar dan (2) Persebaran Masyarakat MBR, diperoleh dari Badan Pemberdayaan Perempuan, Perlindungan Anak dan Keluarga Berencana.

Supaya dapat menjawab pertanyaan mengenai faktor dominan yang mempengaruhi rendahnya preferensi masyarakat terhadap Rusunawa Brujul, maka digunakanlah analisis faktor. Penelitian ini menggunakan kuisioner yang dalam setiap pertanyaan terdapat 5 pilihan jawaban, yaitu: sangat setuju, setuju, netral, tidak setuju dan sangat tidak setuju. Dalam menganalisis data dalam penelitian ini dilakukan beberapa langkah pengolahan data, yaitu:

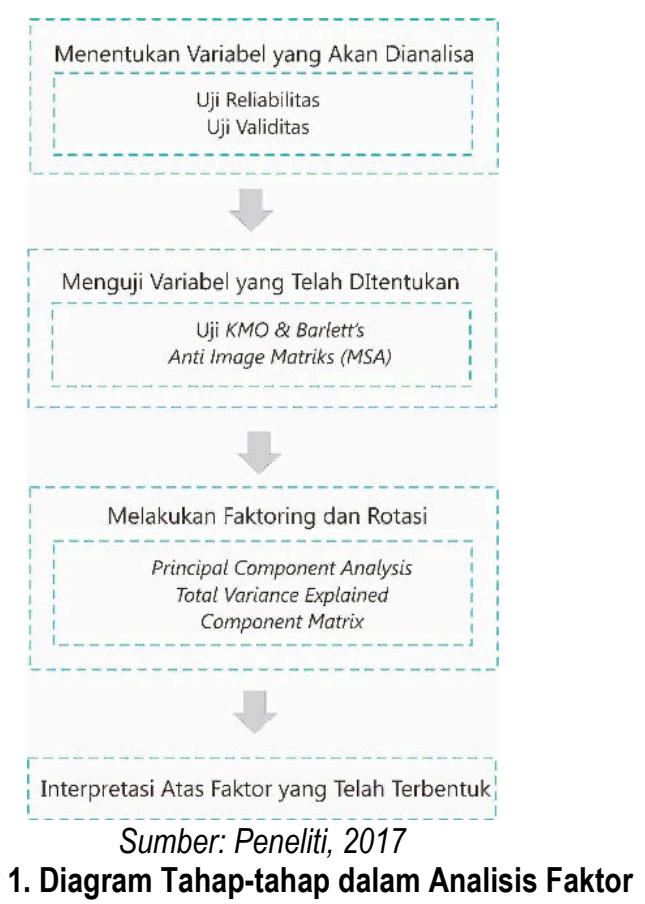

\section{HASIL DAN PEMBAHASAN}

Berdasarkan hasil analisis, dalam hal ini akan dijabarkan mengenai pembahasan dari masing-masing faktor berdasarkan hasil analisis faktor yang dilakukan. Berikut ini merupakan data yang didapat berdasarkan variabel yang ada:

1) Lokasi

Lokasi merupakan salah satu variabel yang ada dalam penelitian ini. Gambar 2 hingga gambar 10 dibawah ini merupakan peta keterjangkauan dari fasilitas-fasilitas yang ada di Kecamatan Jaten terhadap Rusunawa Brujul. 


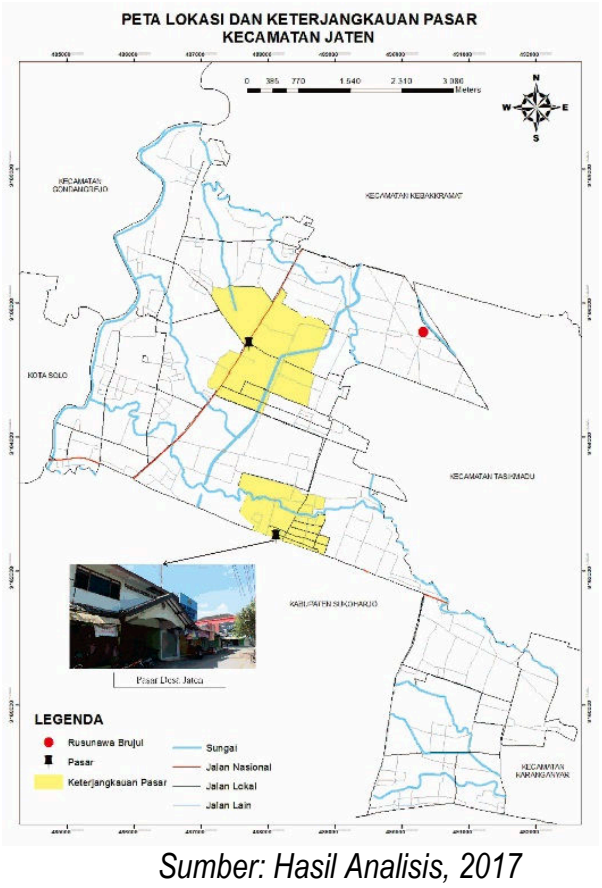

Gambar 2. Peta Lokasi dan Keterjangkauan Pasar Kecamatan Jaten

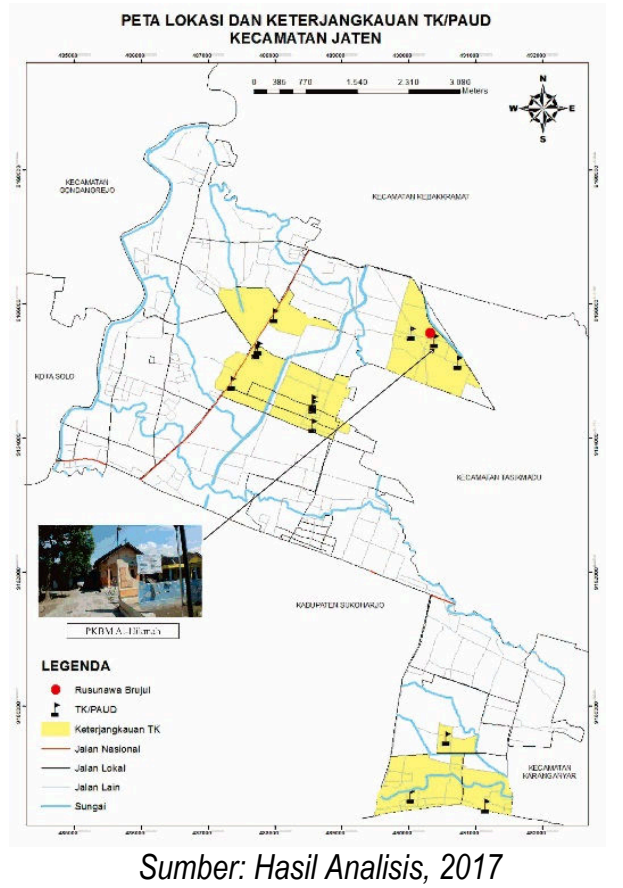

Gambar 3. Peta Lokasi dan Keterjangkauan TK/PAUD Kecamatan Jaten

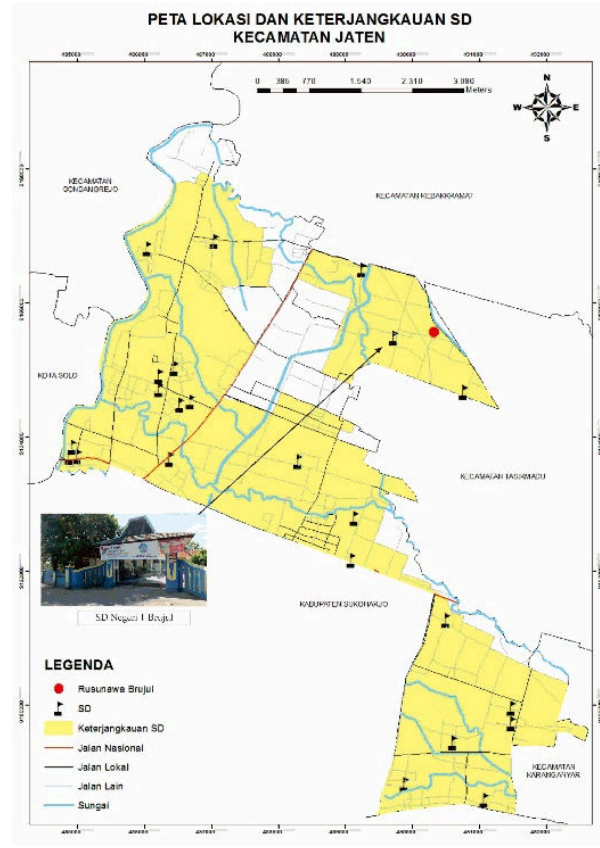

Sumber: Hasil Analisis, 2017

Gambar 4. Peta Lokasi dan Keterjangkauan SD Kecamatan Jaten

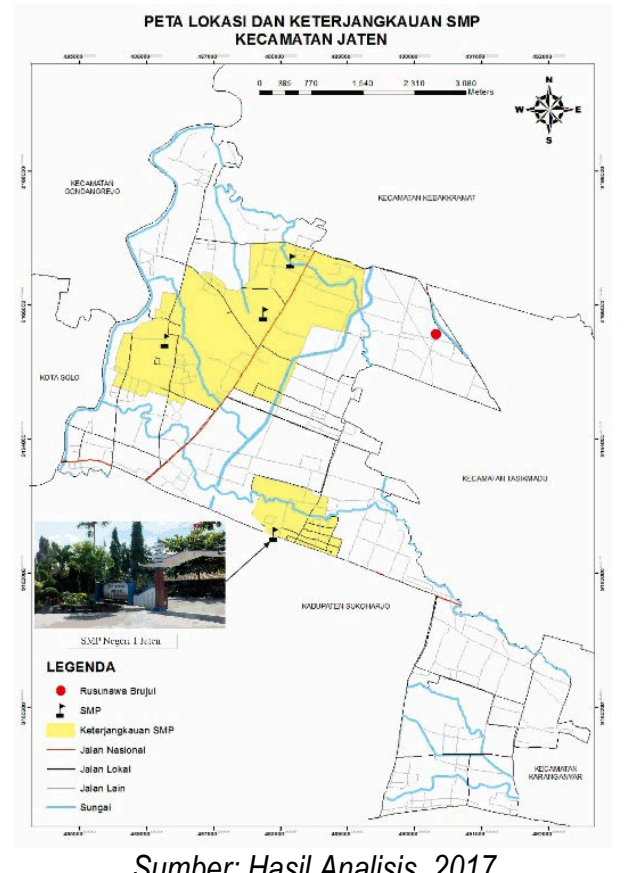

Gambar 5. Peta Lokasi dan Keterjangkauan SMP Kecamatan Jaten 


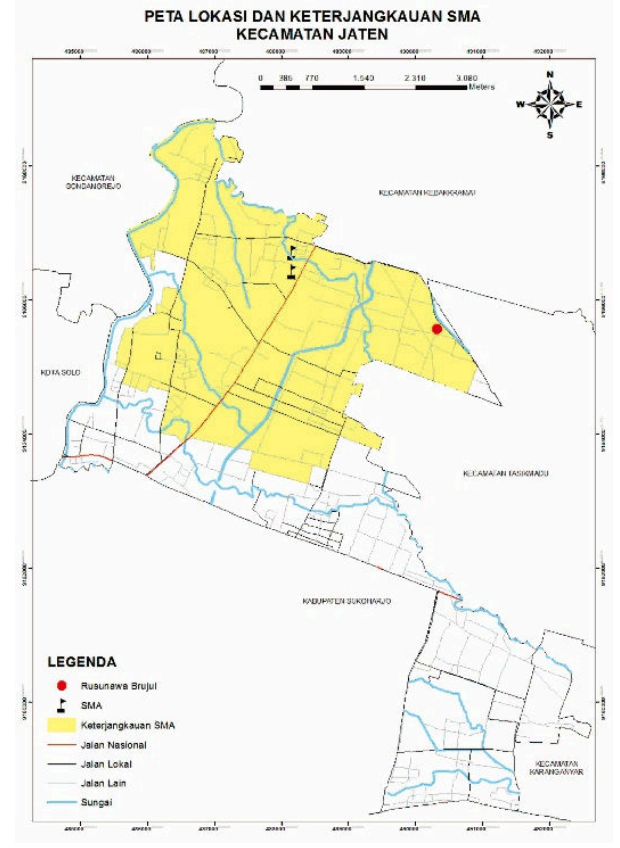

Sumber: Hasil Analisis, 2017

Gambar 6. Peta Lokasi dan Keterjangkauan SMA Kecamatan Jaten

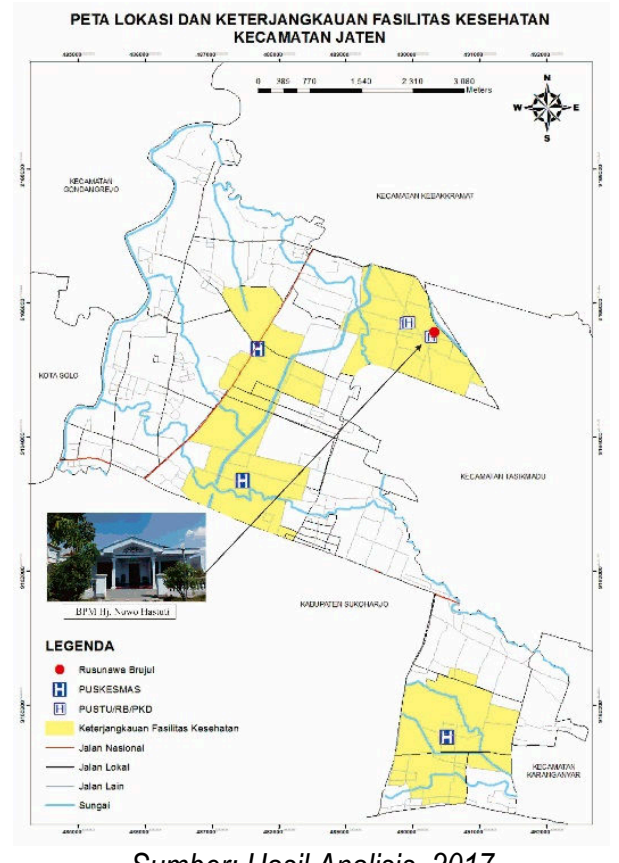

Sumber: Hasil Analisis, 2017

Gambar 7. Peta Lokasi dan Keterjangkauan Fasilitas Kesehatan Kecamatan Jaten

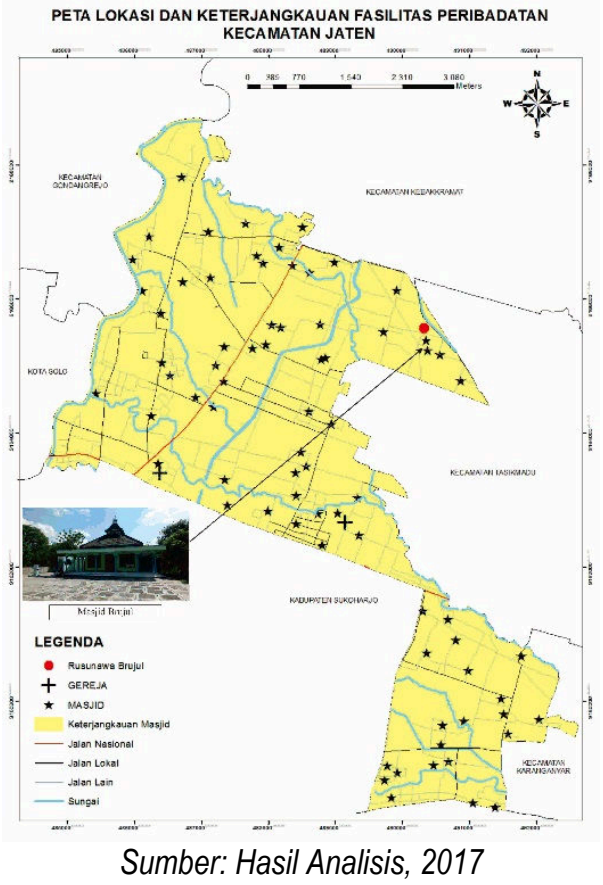

Gambar 8. Peta Lokasi dan Keterjangkauan Fasilitas Peribadatan Kecamatan Jaten

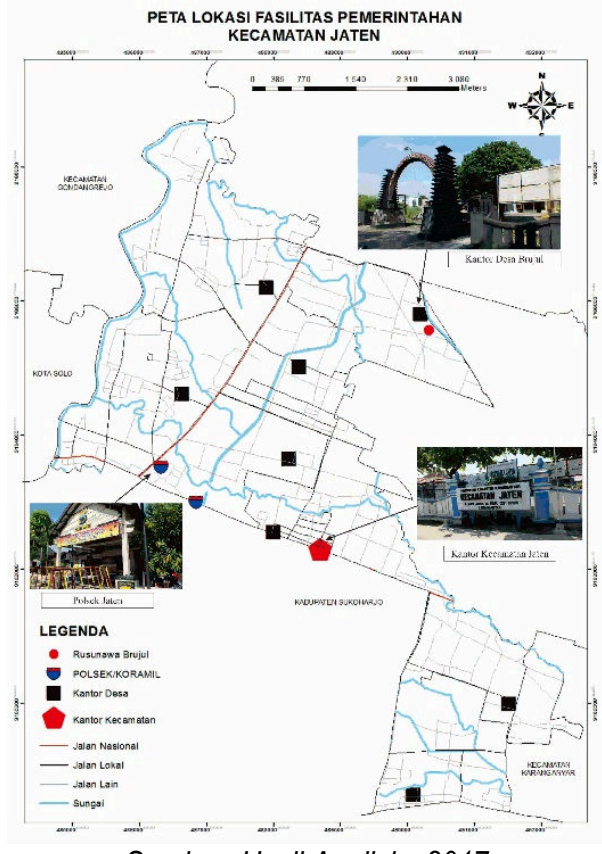

Sumber: Hasil Analisis, 2017

Gambar 9. Peta Lokasi dan Keterjangkauan Fasilitas Pemerintahan Kecamatan Jaten 




Tabel 1 berikut ini merupakan rangkuman data mengenai keterjangkauan dari parameter yang ada di variabel lokasi berupa lokasi kerja dan lokasi fasilitas-fasilitas yang ada di Kecamatan Jaten.

Tabel 1. Data Keterjangkauan Lokasi (Sumber: Hasil Analisis, 2017)

\begin{tabular}{|l|l|l|l|}
\hline No & \multicolumn{1}{|c|}{ Lokasi } & \multicolumn{1}{|c|}{ Keterjangkauan } & \multicolumn{1}{c|}{ Keterangan } \\
\hline 1. & Kerja & \multicolumn{1}{|c|}{ - } & $\begin{array}{l}\text { Lokasi kerja dari masyarakat terletak tersebar di } \\
\text { Kecamatan Jaten maupun Kabupaten } \\
\text { Karanganyar. Terdapat masyarakat yang } \\
\text { berwiraswasta di rumah maupun di pasar. Ada } \\
\text { pula masyarakat yang bekerja sebagai buruh di } \\
\text { pabrik-pabrik di Kecamatan Jaten. }\end{array}$ \\
\hline 2. & Fasilitas Niaga & $\begin{array}{l}\text { Tidak terjangkau pasar yang ada } \\
\text { di Kecamatan Jaten. }\end{array}$ & $\begin{array}{l}\text { Dekat dengan pasar yang ada di kecamatan lain } \\
\text { dan terdapat warung yang dapat memenuhi } \\
\text { kebutuhan penghuni. }\end{array}$ \\
\hline 3. & Fasilitas Pendidikan & $\begin{array}{l}\text { a. TK/PAUD : Terjangkau } \\
\text { b. SD : Terjangkau } \\
\text { c. SMP : Tidak Terjangkau } \\
\text { d. SMA : Terjangkau }\end{array}$ & $\begin{array}{l}\text { Untuk SMP, terdapat sekolah yang berada di } \\
\text { kecamatan lain dan dekat dengan Rusunawa } \\
\text { Brujul sehingga dapat memenuhi kebutuhan } \\
\text { akan pendidikan SMP. }\end{array}$ \\
\hline 4. & Fasilitas Kesehatan & Terjangkau & $\begin{array}{l}\text { Kecamatan Jaten tidak memiliki rumah sakit, } \\
\text { tetapi terdapat puskesmas dan bidan praktek } \\
\text { mandiri yang dapat memenuhi kebutuhan } \\
\text { penghuni di bidang kesehatan. }\end{array}$ \\
\hline 5. & Fasilitas Peribadatan & $\begin{array}{l}\text { Gereja terletak agak jauh dari Rusunawa Brujul } \\
\text { tetapi masih termasuk kedalam wilayah } \\
\text { jangkauannya. }\end{array}$ \\
\hline b. Gereja : Terjangkau & $\begin{array}{l}\text { Kantor Desa Brujul terletak kurang lebih 500 m } \\
\text { dari Rusunawa Brujul. Tetapi, kantor Kecamatan } \\
\text { Jaten terletak kurang lebih 7 km dari Rusunawa } \\
\text { Brujul. }\end{array}$ \\
\hline 7. & Fasilitas Pemerintahan & Terjangkau & $\begin{array}{l}\text { Rusunawa Brujul termasuk kedalam wilayah } \\
\text { jangkauan lapangan Brujul. Untuk makam, } \\
\text { Rusunawa Brujul berada paling dekat dengan } \\
\text { Desa Dagen atau Desa Sroyo. }\end{array}$ \\
\hline
\end{tabular}


2) Fasilitas

Fasilitas di rusun merupakan salah satu variabel yang mempengaruhi rendahnya preferensi masyarakat terhadap Rusunawa Brujul. Parameter dari fasilitas terdiri dari ketersediaan dan kondisi dari masing-masing fasilitas di rusun. Tabel 2 dibawah ini merupakan rangkuman data dari ketersediaan dan kondisi fasilitas yang ada di Rusunawa Brujul.

Tabel 2. Data Ketersediaan dan Kondisi Fasilitas di Rusunawa Brujul

\begin{tabular}{|l|l|l|l|l|}
\hline No & \multicolumn{1}{|c|}{ Fasilitas } & Ketersediaan & \multicolumn{1}{|c|}{ Kondisi } & \multicolumn{1}{|c|}{ Keterangan } \\
\hline 1. & Ruang Umum & Tersedia & $\begin{array}{l}\text { Kurang terawat, karena hanya dibersihkan } \\
\text { apabila akan dilaksanakan acara. }\end{array}$ & \\
\hline 2. & Jalan Setapak & Tersedia & $\begin{array}{l}\text { Terdapat jalan berlumut pada jalan yang } \\
\text { jarang terkena sinar matahari dan jarang } \\
\text { dilewati orang. }\end{array}$ & $\begin{array}{l}\text { Terbuat dari paving } \\
\text { sehingga dapat menyerap } \\
\text { air saat hujan. }\end{array}$ \\
\hline 3. & Jalan Kendaraan & Tersedia & Sudah cukup lebar. & $\begin{array}{l}\text { Terbuat dari paving } \\
\text { sehingga dapat menyerap } \\
\text { air saat hujan. }\end{array}$ \\
\hline 4. & Jalan Selasar & Tersedia & $\begin{array}{l}\text { Sudah bagus karena sudah berkeramik. } \\
\text { Tetapi terlihat penuh karena terdapat barang- } \\
\text { barang penghuni maupun jemurannya. }\end{array}$ & \\
\hline 5. & Tempat Parkir & Tersedia & $\begin{array}{l}\text { Tempat parkir motor hanya dipakai di blok 2 } \\
\text { dan blok 3 agar mudah dikontrol, karena } \\
\text { apabila dipisah berdasarkan blok, maka } \\
\text { tempat parkir tidak pernah penuh. }\end{array}$ & \\
\hline
\end{tabular}

Sumber: Observasi Lapangan, 2017

3) Harga

Harga sewa unit di rusun beragam, tergantung kepada di lantai berapa ia tinggal. Selain itu, pembayaran juga berdasarkan jumlah listrik yang penghuni gunakan. Rata-rata, penghuni mengeluarkan sebesar Rp250.000 perbulan untuk tinggal di Rusunawa. Biaya ini sudah termasuk harga sewa sesuai lantai, uang ledeng sebesar Rp20.000 perbulan, uang kebersihan sebesar Rp15.000 perbulan, dan juga listrik yang digunakan oleh penghuni. Tabel 3 dibawah ini merupakan daftar harga sewa unit perlantai di Rusunawa Brujul.

Tabel 3. Harga Sewa Per Lantai

\begin{tabular}{|c|c|}
\hline Lantai & Harga Sewa \\
\hline 1 & Rp80.000,00 \\
\hline 2 & Rp70.000,00 \\
\hline 3 & Rp60.000,00 \\
\hline
\end{tabular}

4) Standar Unit Rusun

Sumber: Wawancara, 2017

Kondisi unit rusun di Rusunawa Brujul hanya terdiri dari 1 ruang besar, 1 kamar mandi dan 1 balkon di belakang rusun. Untuk unit yang terdapat penghuninya, unit rusun terlihat masih terawat. Akan tetapi untuk unit yang tidak terdapat penghuninya, kondisi unit rusun terlihat sangat tidak terawat. Sistem penghawaan dan pencahayaan unit terdapat pintu di depan menuju jalan selasar dan pintu di belakang untuk ke kamar mandi dan balkon. Selain itu, penghawaan dan pencahayaan di rusun juga berasal dari jendela yang ada di depan unit rusun. Antara satu unit dan unit lainnya dibatasi oleh tembok. Gambar 11 menunjukkan kondisi unit di Rusunawa Brujul yang ditinggali dan unit yang tidak ditinggali oleh penghuni. 


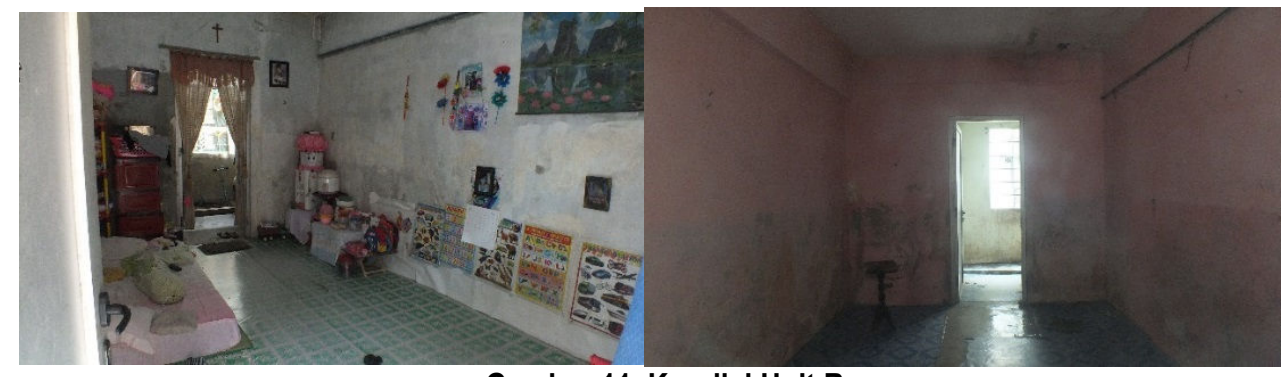

Gambar 11. Kondisi Unit Rusun

Sumber: Observasi Lapangan, 2017

5) Keamanan

- Keamanan

Rusunawa Brujul merupakan salah satu rusunawa yang memiliki tingkat keamanan yang tinggi. Di Rusunawa Brujul sendiri hanya pernah terjadi pencurian sekali. Pencurian tersebut juga dilakukan oleh teman dari penghuni sendiri. Selain itu, belum pernah ada kasus yang lain. Di Rusunawa Brujul juga tidak terdapat orang yang melakukan mabuk-mabukan.

- Keamanan Anak

Di Rusunawa Brujul tidak pernah ada kasus dimana saat anak bermain, anak-anak terjatuh dari lantai atas. Hal ini didukung dengan Rusunawa Brujul yang memiliki pagar yang cukup tinggi, sehingga apabila anak-anak bermain maka tidak akan terjadi hal yang tidak diinginkan.

6) Kenyamanan

Masyarakat menganggap apabila tinggal di rusun, maka kenyamanan yang didapat akan berkurang, tidak seperti di tempat tinggal saat ini. Menurut penhuni rusun, memang kenyamanan yang didapat di rusun masih sedikit kurang. Hal ini dipengaruhi dari berbagai faktor yang ada.

7) Lingkungan Sosial

Masyarakat di Kecamatan Jaten masih sangat senang memiliki interaksi sosial dengan masyarakat lainnya. Masyarakat sudah nyaman dengan lingkungan sosialnya saat ini. Masyarakat takut apabila pindah ke rusun, maka lingkungan sosialnya akan berubah dan juga mempengaruhi interaksi sosial dari masyarakat. Padahal, di Rusunawa Brujul dapat dilihat bahwa penghuni masih dapat berinteraksi sosial dengan baik satu sama lainnya.

Sebelum melakukan analisis faktor, langkah pertama adalah melakukan uji reliabilitas dan uji validitas. Berikut ini merupakan hasil dari uji reliabilitas dan uji validitas.

1) Uji Reliabilitas

Untuk melihat instrumen reliabel atau tidak dapat dilihat dari nilai Cronbach's Alpha yang harus $>0,8$. Dalam penelitian ini, instrumen yang diajukan sudah reliabel karena nilai dari Cronbach's Alpha adalah 0,979. Tabel 4 dibawah merupakan hasil dari uji reliabilitas yang digunakan untuk mengetahui apakah parameter yang digunakan sudah reliabel atau belum.

Tabel 4. Hasil Uji Reliabilitas

Reliability Statistics

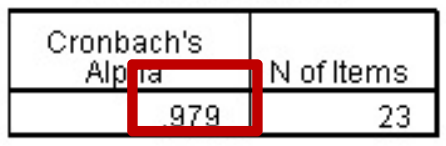

Sumber: Hasil Analisis, 2017

2) Uji Validitas

Uji validitas dilakukan untuk mengetahui sejauh mana nilai dari instrumen penelitian. Sebuah pertanyaan dapat dikatakan valid apabila nilai Corrected Item-Total Correlation lebih dari nilai r. Nilai $r$ dalam penelitian dapat titentukan dengan melihat tabel $r$, dengan ketentuan $\mathrm{df}=$ jumlah kasus -2 . Sehingga didapatkan $\mathrm{df}=120-2=$ 118 , dengan tingkat signifikansi sebesar $5 \%$. Maka nilai $r$ nya adalah 0,1509 . Dapat dilihat bahwa dalam instrumen ini, bahwa semua nilai Corrected Item - Total Correlation berada diatas 0,1509. Maka dapat disimpulkan bahwa 23 pertanyaan yang diajukan sudah valid. Tabel 5 dibawah merupakan hasil uji validitas dari masing-masing parameter yang digunakan dalam penelitian ini. 
Tabel 5. Hasil Uji Validitas

\begin{tabular}{|c|c|c|c|c|}
\hline \multicolumn{5}{|c|}{ Item-Total Statistics } \\
\hline & $\begin{array}{l}\text { Scale Mean if } \\
\text { Item Deleted }\end{array}$ & $\begin{array}{c}\text { Scale } \\
\text { variance if } \\
\text { ltem Deleted }\end{array}$ & $\begin{array}{l}\text { Corrected } \\
\text { Item-Total } \\
\text { Comerostion }\end{array}$ & $\begin{array}{l}\text { Cronbach's } \\
\text { Alpha if tem } \\
\text { Deleted }\end{array}$ \\
\hline $\begin{array}{l}\text { KETERSEDIAAN_ } \\
\text { RUANGUMUM }\end{array}$ & 99.27 & 207.525 & .874 & .977 \\
\hline $\begin{array}{l}\text { KETERSEDIAAN } \\
\text { JALANSETAPAK }\end{array}$ & 99.41 & 202.597 & .925 & .977 \\
\hline $\begin{array}{l}\text { KETERSEDIAAN } \\
\text { JALANKENDARAAAN }\end{array}$ & 99.28 & 207.902 & .837 & .978 \\
\hline $\begin{array}{l}\text { KETERSEDIAAN- } \\
\text { JALANSELASAR }\end{array}$ & 99.24 & 209.983 & .850 & .978 \\
\hline $\begin{array}{l}\text { KETERSEDIAAN } \\
\text { TEMPATPARKIR }\end{array}$ & 99.31 & 206.635 & .842 & .977 \\
\hline KONDISI_RUANGUMUM & 99.28 & 208.289 & .915 & .977 \\
\hline $\begin{array}{l}\text { KONDISI } \\
\text { JALANSETAPAK }\end{array}$ & 99.34 & 205.403 & .939 & .977 \\
\hline $\begin{array}{l}\text { KONDISI } \\
\text { JALANKENDARAAN }\end{array}$ & 99.25 & 209.685 & .928 & .977 \\
\hline $\begin{array}{l}\text { KONDISI } \\
\text { JALANSELASAR }\end{array}$ & 99.25 & 209.685 & .928 & .977 \\
\hline $\begin{array}{l}\text { KONDISI } \\
\text { TEMPATPARKIR }\end{array}$ & 99.28 & 207.180 & .888 & .977 \\
\hline LOKASI_KERJA & 99.75 & 212.155 & .516 & .980 \\
\hline LOKASI_NIAGA & 99.45 & 201.880 & .811 & .978 \\
\hline LOKASI_PENDIDIKAN & 99.43 & 201.727 & .910 & .977 \\
\hline LOKASI_KESEHATAN & 99.48 & 201.580 & .865 & .977 \\
\hline LOKASI_PERIBADATAN & 99.26 & 208.496 & .842 & .978 \\
\hline LOKASI_PEMERINTAHAN & 99.87 & 193.780 & .896 & .978 \\
\hline $\begin{array}{l}\text { LOKASI } \\
\text { RUANGTERBUKA }\end{array}$ & 99.14 & 215.534 & .794 & .978 \\
\hline HARGA & 99.09 & 219.227 & .494 & .980 \\
\hline STANDAR_UNIT_RUSUN & 99.34 & 205.403 & .939 & .977 \\
\hline KEAMANAN & 99.70 & 201.371 & .820 & .978 \\
\hline KEAMANAN_ANAK & 99.31 & 205.913 & .917 & .977 \\
\hline KENYAMANAN & 99.44 & 201.795 & .888 & .977 \\
\hline LINGKUNGAN_SOSIAL & 99.25 & 216.055 & .408 & .981 \\
\hline
\end{tabular}

Tabel 6 berikut ini merupakan hasil analisis dari faktor-faktor baru yang terbentuk dari hasil proses analisis faktor berdasarkan kuisioner yang telah disebarkan.

Tabel 6. Faktor-faktor yang Terbentuk

\begin{tabular}{|c|c|c|c|c|c|c|c|c|c|}
\hline \multirow[b]{2}{*}{$\begin{array}{l}\text { Faktor yang } \\
\text { terbentuk }\end{array}$} & \multirow[b]{2}{*}{$\begin{array}{c}\% \text { of } \\
\text { Variance }\end{array}$} & \multirow[b]{2}{*}{ Parameter } & \multirow[b]{2}{*}{$\begin{array}{l}\text { Loading } \\
\text { factor }\end{array}$} & \multicolumn{5}{|c|}{ Tingkat Pengaruh (\%) } & \multirow[b]{2}{*}{$\begin{array}{l}\text { Total } \\
(\%)\end{array}$} \\
\hline & & & & $\begin{array}{c}5 \\
\text { SS }\end{array}$ & $\begin{array}{l}4 \\
S\end{array}$ & $\begin{array}{l}3 \\
\mathrm{~N}\end{array}$ & $\begin{array}{c}2 \\
\text { TS }\end{array}$ & $\begin{array}{c}1 \\
\text { STS }\end{array}$ & \\
\hline \multirow{14}{*}{$\begin{array}{l}\text { Faktor Keadaan } \\
\text { Rusun }\end{array}$} & \multirow{14}{*}{71,89} & Ketersediaan Ruang Umum & 0,673 & 72,5 & 19,17 & 5,83 & 2,5 & & 100 \\
\hline & & Ketersediaan Jalan Setapak & 0,691 & 66,67 & 18,33 & 11,67 & 2,5 & 0,83 & 100 \\
\hline & & $\begin{array}{l}\text { Ketersediaan Jalan } \\
\text { Kendaraan }\end{array}$ & 0,882 & 71,67 & 19,17 & 6,67 & 2,5 & & 100 \\
\hline & & Ketersediaan Jalan Selasar & 0,828 & 70,83 & 24,17 & 3,33 & 1,67 & & 100 \\
\hline & & Ketersediaan Tempat Parkir & 0,880 & 70,83 & 20 & 5 & 4,17 & & 100 \\
\hline & & Kondisi Ruang Umum & 0,720 & 69,17 & 21,67 & 9,17 & & & 100 \\
\hline & & Kondisi Jalan Setapak & 0,743 & 67,5 & 20,83 & 10 & 1,67 & & 100 \\
\hline & & Kondisi Jalan Kendaraan & 0,797 & 70 & 20 & 7,5 & 2,5 & & 100 \\
\hline & & Kondisi Jalan Selasar & 0,797 & 69,17 & 25 & 5,83 & & & 100 \\
\hline & & Kondisi Tempat Parkir & 0,879 & 70,83 & 20,83 & 5,83 & 2,5 & & 100 \\
\hline & & Standar Unit Rusun & 0,659 & 79,17 & 13,33 & 5,83 & 1,67 & & 100 \\
\hline & & Keamanan & 0,565 & 74,17 & 25,83 & & & & 100 \\
\hline & & Keamanan Anak & 0,825 & 70 & 23,33 & 5,83 & 0,83 & & 100 \\
\hline & & Kenyamanan & 0,642 & 72,5 & 20 & 5 & 2,5 & & 100 \\
\hline \multirow{7}{*}{ Faktor Lokasi } & \multirow{7}{*}{5,49} & Lokasi Fasilitas Niaga & 0,631 & 70 & 12,5 & 10 & 5,83 & 1,67 & 100 \\
\hline & & Lokasi Fasilitas Pendidikan & 0,708 & 67,5 & 15 & 13,33 & 3,33 & 0,84 & 100 \\
\hline & & Lokasi Fasilitas Kesehatan & 0,743 & 65 & 17,5 & 10,83 & 5,83 & 0,83 & 100 \\
\hline & & Lokasi Fasilitas Peribadatan & 0,693 & 65 & 19,17 & 10 & 5 & 0,83 & 100 \\
\hline & & Lokasi Fasilitas Pemerintahan & 0,699 & 48,33 & 24,17 & 11,67 & 10 & 5,83 & 100 \\
\hline & & $\begin{array}{l}\text { Lokasi Fasilitas Ruang } \\
\text { Terbuka }\end{array}$ & 0,673 & 46,67 & 35,83 & 10,83 & 2,5 & 4,17 & 100 \\
\hline & & Lokasi Kerja & 0,710 & 75,83 & 16,67 & 3,33 & 3,33 & 0,83 & 100 \\
\hline Faktor Sosial & 4,78 & Harga & 0,685 & 80,83 & 17,5 & 1,67 & & & 100 \\
\hline
\end{tabular}




\begin{tabular}{|c|c|c|c|c|c|c|c|c|c|}
\hline \multirow{3}{*}{$\begin{array}{c}\text { Faktor yang } \\
\text { terbentuk } \\
\text { Ekonomi }\end{array}$} & \multirow{3}{*}{$\begin{array}{c}\% \text { of } \\
\text { Variance }\end{array}$} & \multirow[b]{2}{*}{ Parameter } & \multirow[b]{2}{*}{$\begin{array}{l}\text { Loading } \\
\text { factor }\end{array}$} & \multicolumn{5}{|c|}{ Tingkat Pengaruh (\%) } & \multirow[b]{2}{*}{$\begin{array}{c}\text { Total } \\
(\%)\end{array}$} \\
\hline & & & & $\begin{array}{c}5 \\
\text { SS }\end{array}$ & $\begin{array}{l}4 \\
5\end{array}$ & $\begin{array}{l}3 \\
\mathrm{~N}\end{array}$ & $\begin{array}{c}2 \\
T S\end{array}$ & $\begin{array}{c}1 \\
\text { STS }\end{array}$ & \\
\hline & & Lingkungan Sosial & 0,858 & 33,33 & 55,83 & 4,17 & 4,17 & 2,5 & 100 \\
\hline
\end{tabular}

Sumber: Hasil Analisis, 2017

Dari analisis yang telah dilakukan, maka dapat disimpulkan bahwa semua parameter yang digunakan pada tahap awal termasuk kedalam kelompok faktor-faktor dominan yang mempengaruhi rendahnya preferensi masyarakat terhadap Rusunawa Brujul. Dari 23 parameter yang terdapat pada tahap awal, maka terbentuklah 3 kelompok faktor dominan yang merupakan pengelompokan dari 23 parameter yang ada. Kelompok faktor dominan pertama adalah faktor keadaan rusun yang memiliki nilai sebesar $71,89 \%$. Kelompok faktor keadaan rusun termasuk didalamnya ketersediaan dan kondisi fasilitas rusun, kondisi unit rusun, keamanan serta kenyamanan. Kelompok faktor dominan kedua adalah faktor lokasi yang memiliki nilai sebesar $5,49 \%$. Kelompok faktor lokasi temasuk didalamnya adalah pengaruh lokasi fasilitas umum dan lokasi kerja. Kelompok faktor dominan ketiga yang memiliki nilai terendah adalah faktor sosial ekonomi, yakni sebesar $4,78 \%$. Kelompok faktor lokasi termasuk didalamnya adalah harga dan lingkungan. Maka dari itu dapat disimpulkan bahwa kelompok faktor yang paling berpengaruh dalam rendahnya preferensi masyarakat terhadap Rusunawa Brujul adalah faktor keadaan rusun.

\section{KESIMPULAN}

Terdapat tiga kelompok faktor dominan yang mempengaruhi rendahnya preferensi masyarakat terhadap Rusunawa Brujul. Kelompok faktor dominan pertama yang mempengaruhi adalah faktor keadaan rusun dengan nilai sebesar $71,89 \%$. Kelompok faktor dominan kedua yang mempengaruhi adalah faktor lokasi dengan nilai sebesar $5,49 \%$. Kelompok faktor dominan ketiga adalah faktor sosial ekonomi dengan nilai sebesar 4,78\%.

\section{DAFTAR PUSTAKA}

\section{Buku}

Nugroho, M.D.A. (2014). Faktor-Faktor Penyebab Kurang Diminatinya Rumah Susun Sederhana Sewa Tanah Merah I dan Tanah Merah II Kelurahan Tanah Kalikedinding Kecamatan Kenjeran Kota Surabaya (Menurut Persepsi Masyarakat Kelurahan Tanah Kalikedinding). Surabaya: Universitas Negeri Surabaya.

Harianto, Y.H. (2006). Analisis Faktor-Faktor yang Mempengaruhi Perceived Quality dan Dampaknya Terhadap Brand Equity (Kajian Pada Produk Elektronik Merk Sony di Kota Semarang). Semarang: Universitas Diponegoro Semarang.

Nasution, R.A. (2004). Faktor-faktor yang Mempengaruhi Penghuni Baru Untuk Memilih Tinggal di Rumah Susun Klender Jakarta Timur. Semarang: Universitas Diponegoro.

Sasmito, A.A. (2014). Faktor Penyebab Rendahnya Minat Warga Kampung Juminahan untuk Menghuni Rumah Susun Graha Bina Harapan Tegalpanggung Yogyakarta. Yogyakarta: Universitas Gadjah Mada.

\section{Dokumen Pemerintah yang Tersedia Online}

Badan Pusat Statistik. Kecamatan Jaten dalam Angka Tahun 2016

\section{Buku Referensi Lainnya}

Junaidi. (2010), “Tabel R (Koefisien Korelasi Sederhana) df = 1-200" http://junaidichaniago.wordpress.com (diakses 30 Mei 2017)

\section{Surat Kabar}

Aditya, I. (2016), "Rusunawa Brujul Tampung Warga Eksodus Nglano." http://krjogja.com/web/news/read/4717/Rusunawa_Brujul_Tampung_Warga_Eksodus_Nglano (diakses 15 Oktober 2016)

Sinombor, S.H. (2008). "Dibangun 1.000 Rumah dan Rusunawa Untuk Pekerja di Karanganyar." http://megapolitan.kompas.com/read/2008/04/02/17013846/dibangun.1.000.rumah.dan.rusunawa.untuk.pekeria.di.karangan yar. (diakses 12 Mei 2017)

Widiyanto, D. (2016), "Rusunawa Brujul Tak Diminati, Pemkab Bingung." http://kriogja.com/web/news/read/7494/Rusunawa_Brujul_Tak_Diminati_Pemkab_Bingung (diakses 15 Oktober 2016). 